Schötz, Theresa; Ponce de Leon, Carlos; Ueda, Mikito; Bund, Andreas:

State of the art of rechargeable aluminum batteries in non-aqueous systems

Original published in: Journal of the Electrochemical Society : JES. - Pennington, NJ : Electrochemical Soc. - 164 (2017), 14, p. 3499-3502.

Original published: $\quad$ 2017-11-14

ISSN:

$1945-7111$

DOI: $\quad 10.1149 / 2.0311714 \mathrm{jes}$

[Visited: 2019-03-28]

(c) (1)

This work is licensed under a Creative Commons Attribution 4.0 International license. To view a copy of this license, visit http://creativecommons.org/licenses/by/4.0/ 


\title{
State of the Art of Rechargeable Aluminum Batteries in Non-Aqueous Systems
}

\author{
T. Schoetz, ${ }^{\mathrm{a}, \mathrm{z}}$ C. Ponce de Leon, ${ }^{\mathrm{a}}$ M. Ueda, ${ }^{\mathrm{b}, *}$ and A. Bund $\odot{ }^{\mathrm{c}, *}$ \\ ${ }^{a}$ Faculty of Engineering and the Environment, University of Southampton, Highfield Southampton SO17 1 BJ, \\ United Kingdom \\ ${ }^{b}$ Faculty of Engineering, Hokkaido University, Sapporo, 060-8628 Hokkaido, Japan \\ ${ }^{c}$ Electrochemistry and Electroplating Group, Technische Universität Ilmenau, 98693 Ilmenau, Germany
}

\begin{abstract}
The main challenges to implement sustainable energy storage technologies are the utilization of earth-abundant recyclable materials, low costs, safe cell reactions and high performance, all in a single system. Aluminum batteries seem to cover these requirements. However, their practical performance is still not comparable with the state of the art high performance batteries. A key aspect to further development could be the combination of aluminum with charge storage materials like conductive polymers in non-aqueous electrolytes taking advantage of the properties of each material. This review presents the approaches and perspectives for rechargeable aluminum-based batteries as sustainable high-performance energy storage devices.

(C) The Author(s) 2017. Published by ECS. This is an open access article distributed under the terms of the Creative Commons Attribution 4.0 License (CC BY, http://creativecommons.org/licenses/by/4.0/), which permits unrestricted reuse of the work in any medium, provided the original work is properly cited. [DOI: 10.1149/2.0311714jes] All rights reserved.

(cc) BY
\end{abstract}

Manuscript submitted October 2, 2017; revised manuscript received November 2, 2017. Published November 14, 2017.

The storage of electricity is a key component in the drive to a sustainable energy society. However, current energy storage devices, like high performance lithium-ion batteries, have constrained raw material resources, difficult recycling process and danger of flammability. Far less attention has been directed to the use lightweight aluminum based batteries in non-aqueous systems as aluminum has lower cost, is more abundant and is safer than lithium. Furthermore, its specific capacity of $2980 \mathrm{mAh} \mathrm{g}^{-1}$ and volumetric capacity of $8040 \mathrm{mAh} \mathrm{cm}^{-3}$, respectively, are higher than lithium. ${ }^{1}$

The number of studies on rechargeable aluminum-based batteries in non-aqueous systems has increased 10-fold in the last decade (Figure 1). Therefore, it seems appropriate and timely to review the state of the art and the implementation of novel ideas and approaches made for rechargeable high performance aluminum-based batteries and reflect on the perspectives, challenges and limitations that these relatively new systems face.

Gifford et al. described this novel battery system in 1988 with aluminum and graphite as the negative and positive electrodes respectively, in a Lewis acidic chloroaluminate ionic liquid at room temperature. Chloroaluminate anions intercalated into the graphite electrode reaching $64 \mathrm{Wh} \mathrm{kg}^{-1}$ specific energy at $1.7 \mathrm{~V}$ discharge voltage over 150 cycles and $80-90 \%$ coulombic efficiency. ${ }^{2}$ The same idea was taken up several years later by various research groups ${ }^{1,3-5}$ using different oxides, sulfides and zeolites materials as intercalation electrodes. ${ }^{6-13}$ More recently the introduction of conductive polymers (CP) as intercalation electrode sets a further development with great potential for a rechargeable aluminum hybrid battery-capacitor energy storage system. ${ }^{14,15}$

\section{Current Status- Conventional Aluminum Based Batteries with Aqueous Electrolyte}

A number of primary battery compositions like Al- $\mathrm{MnO}_{2}$, Al$\mathrm{AgO}, \mathrm{Al}-\mathrm{H}_{2} \mathrm{O}_{2}, \mathrm{Al}-\mathrm{S}, \mathrm{Al}-\mathrm{FeCN}$ and $\mathrm{Al}-\mathrm{NiOOH}^{16}$ in aqueous electrolyte have been reported. Al-air batteries are characterized by low cost, sustainability and high theoretical specific energies $8100 \mathrm{Wh}$ $\mathrm{kg}^{-1},{ }^{17}$ which are higher than the theoretical values of some lithiumion batteries $\left(600 \mathrm{Wh} \mathrm{kg}^{-1}\right){ }^{18}$ The theoretical specific energy does not consider the weight of the oxygen electroactive species for the positive gas diffusion electrode (GDE) electrode because the battery utilizes oxygen from the atmosphere. ${ }^{19}$ In practice, aluminum-air batteries based on aqueous systems are still characterized by the slow kinetics of the oxygen reduction reaction, even if the aluminum alloy

\footnotetext{
*Electrochemical Society Member.
}

${ }^{\text {z}}$ E-mail: T.Schoetz@soton.ac.uk used, is highly active. In addition, the use of air from the environment seems to be problematic due to the presence of nitrogen and carbon dioxide that could passivate the GDE catalyst. Furthermore, the parasitic corrosion and a passivation of the aluminum electrode, except in very high concentrated alkaline electrolytes, lowers the cell voltage and consequently the battery performance. ${ }^{20,21}$

In general, the use of aqueous electrolytes enables only primary aluminum batteries because the aluminum re-deposition occurs at a more negative potential $\left(-1.66 \mathrm{~V}\right.$ vs. $\left.\mathrm{SHE}^{20}\right)$ than the hydrogen evolution. Secondary aluminum-based batteries are only possible in non-aqueous electrolytes with larger electrochemical stability window.

\section{Future Needs and Prospects}

Introduction of non-aqueous electrolytes.-Secondary batteries can be realized due to the reversible deposition and dissolution of aluminum in non-aqueous electrolytes like molten salts $\mathrm{NaCl}-$ $\mathrm{AlCl}_{3}$ or $\mathrm{NaCl}-\mathrm{KCl}-\mathrm{AlCl}_{3}^{22,23}$ or ionic liquids (quaternary ammonium species) ${ }^{24}$ In non-aqueous electrolytes the passive oxide layer found on the aluminum electrodes, is not formed ${ }^{1,15,17}$ while the electrochemical stability window enables the deposition of aluminum and the realization of higher cell voltages. ${ }^{21}$ In contrast to high temperature molten salts, ionic liquids are liquid at room temperature. ${ }^{24}$

Ionic liquids are widely promoted as green solvents or designer electrolytes, which are water free salts, consisting of weakly coordinated complex ions liquid below $100^{\circ} \mathrm{C}$, or at room temperature. At least one ion has a delocalized charge and one component is organic, which prevents the formation of stable crystal lattices.

The main attraction of the ionic liquids is their characteristic wide electrochemical stability window, usually from 4.5 to $6.0 \mathrm{~V}$. This is more than three times larger than aqueous solutions with maximum of $1.3 \mathrm{~V}$ making them suitable for high-performance electrochemical energy storage devices with electroactive species with redox potentials outside the stability window of water. ${ }^{11,12}$ Furthermore, most ionic liquids show a high thermal stability, non-flammability, non-volatility and a low vapor pressure, offering a much lower toxicity and higher safety in comparison to organic solvents. The substituents of the organic component and the counter-ion, influence the ionic liquid properties like melting point, viscosity, conductivity and solubility. ${ }^{25-27}$

Ionic liquids such as 1-ethyl-3-methylimidazolium, 1,3-di-nbutylimidazolium, 1-butylpyridinium, triazolium, or alphatic onium cation $^{27}$ in combination with chloroaluminate anions can reach a potential window of up to $6 \mathrm{~V}$. In addition, their melting point is around room-temperature with an electric conductivity of $10 \mathrm{mS} \mathrm{cm}{ }^{-1}, 28$ which is within the order of magnitude of most aqueous electrolytes. 


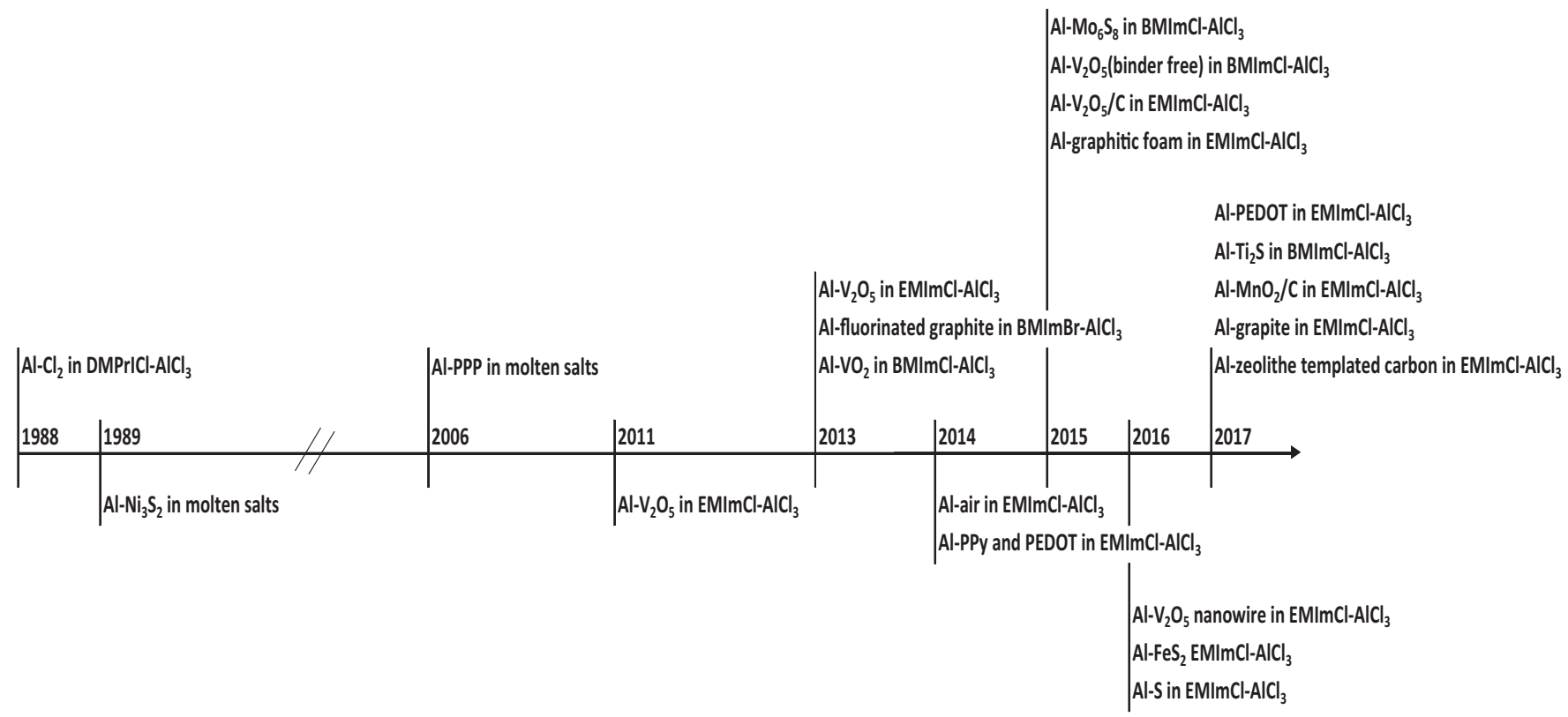

Figure 1. Timeline of significant rechargeable aluminum-based batteries in non-aqueous systems.

Chloroaluminate based ionic liquids are mostly hygroscopic. ${ }^{29}$ Moisture can decompose them or decrease the potential window. For example $3 \mathrm{wt} \%$ of water could decrease the anodic and cathodic potential window from $6 \mathrm{~V}$ to $3 \mathrm{~V} \cdot{ }^{27}$ In contrast to non-chloroaluminate systems, which are mostly Lewis neutral, chloroaluminate ionic liquids can change their acidity by varying the molar composition of the anion and cation components to basic, neutral or acidic, changing their conductivity and viscosity. ${ }^{30}$

The deposition and dissolution of aluminum in quaternary ammonium chloroaluminate based ionic liquids has a current efficiency from $85 \%$ to $100 \%{ }^{29,31,32}$ The typical morphology of deposited aluminum on glassy carbon, tungsten, platinum or aluminum is granular, circular and cluster structures with high adhesion. The repeated deposition and dissolution of aluminum caused only an increase of the microcrystalline surface roughness. Dendrite growth was only observed at high current densities over $100 \mathrm{~mA} \mathrm{~cm}^{-2} \cdot 1,5,15,21,32,33$ The electrodeposition of aluminum on glassy carbon, tungsten and platinum electrodes follows an instantaneous mechanism with diffusion controlled growth, in contrast, the deposition on aluminum electrodes has kinetic limitations. ${ }^{32}$

The deposition (charge reaction) and dissolution (discharge reaction) of aluminum (Equation 1) at the negative electrode is only possible in a Lewis acidic chloroaluminate ionic liquid, containing $\mathrm{Al}_{2} \mathrm{Cl}_{7}{ }^{-} \cdot 24$

$$
4 \mathrm{Al}_{2} \mathrm{Cl}_{7}^{-}+3 \mathrm{e}^{-} \underset{\text { discharge }}{\stackrel{\text { charge }}{\rightleftharpoons}} \mathrm{Al}+7 \mathrm{AlCl}_{4}^{-}
$$

The heptachlorodialuminate $\mathrm{Al}_{2} \mathrm{Cl}_{7}{ }^{-}$anion forms when the molar ratio $N$, of $\mathrm{AlCl}_{3}$ to the ionic liquid cation is higher than 0.5 (Lewis acidic). An excess of the cation and a molar ratio of $\mathrm{AlCl}_{3}$ lower than 0.5 leads to a Lewis basic ionic liquid, owing to the presence of free halide ions (Equation 2). ${ }^{34} \mathrm{~A}$ Lewis neutral composition consist of the same molar ratio of $\mathrm{AlCl}_{3}$ and $\mathrm{EMImCl}\left(\mathrm{N}\right.$ of $\mathrm{AlCl}_{3}$ is 0.5$)$.

$$
2 \mathrm{AlCl}_{4}^{-} \rightleftharpoons \mathrm{Al}_{2} \mathrm{Cl}_{7}^{-}+\mathrm{Cl}^{-}
$$

The properties of the different compositions of an $\mathrm{EMImCl}-\mathrm{AlCl}_{3}$ ionic liquid differ with their acidity. A Lewis acidic composition has the highest density (acidic $1.39 \mathrm{~g} \mathrm{~cm}^{-3}$, basic $1.26 \mathrm{~g} \mathrm{~cm}^{-3}$ and neutral $1.29 \mathrm{~g} \mathrm{~cm}^{-3}$ ), but only a medium conductivity (acidic $15 \mathrm{mS}$ $\mathrm{cm}^{-1}$, basic $6.5 \mathrm{mS} \mathrm{cm}^{-1}$, neutral $23 \mathrm{mS} \mathrm{cm}^{-1}$ ) and viscosity (acidic $14 \mathrm{mPa}$, basic $47 \mathrm{mPa}$ s, neutral $18 \mathrm{mPa} \mathrm{s}$ ). ${ }^{26,27}$ In comparison, the
Lewis neutral composition is characterized by the highest conductivity whereas the Lewis basic composition by the lowest.

Charge-storage materials as positive electrodes in rechargeable aluminum batteries.-Ionic liquid electrolytes, improve the stability and life-time of batteries in contrast to aqueous or organic solvents..$^{6,35,36}$ Proof of concept studies demonstrate that the performance of rechargeable aluminum batteries with an ionic liquid electrolyte can be improved by introducing an active chargestorage material as the positive electrode. Charge-storage materials can reversible intercalate aluminum-anion species of the ionic liquid electrolyte like 1-ethyl-3-methylimidazolium chloride (EMImCl$\left.\mathrm{AlCl}_{3}\right)$ or 1,3-di-n-butylimidazolium bromide $\left(\mathrm{BImBr}-\mathrm{AlCl}_{3}\right)$. Typical positive electrodes include porous and three-dimensional materials

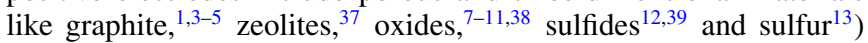
(Table I). Another type of positive electrode materials include conductive polymers ${ }^{14,15,40}$ which also store anions to compensate their positive charges created during the oxidation of the polymer backbone. The aluminum battery systems with graphite, zeolites, sulfides and oxides show high reversibility, cycle stability, constant electrochemical behavior and coulomb efficiencies $>95 \%$.

Aluminum batteries with oxides as the positive electrode show a very high specific discharge capacity. However, low cell voltages and strongly sloping discharge plateaus for oxide, sulfide and zeolite template carbon electrodes, indicated capacitive behavior problems, making it difficult to define the specific energy and power characteristics. In addition, the oxides have a strong electrostatic interaction with the doping anions, which complicate the reversible intercalation mechanism.

Porous three-dimensional graphitic-foam ${ }^{4}$ and pyrolytic graphite ${ }^{1}$ electrodes are also promising; at the graphitic foam positive electrode, the $\mathrm{AlCl}_{4}{ }^{-}$ions are intercalated and de-intercalated between the graphite layers while the metallic aluminum electrode oxidizes to $\mathrm{Al}_{2} \mathrm{Cl}_{7}{ }^{-}$during the discharge cycle and is reduced back to aluminum during the charge cycle. This type of battery shows a high discharge cell voltage of $\sim 2 \mathrm{~V}$ and its specific energy ( $40 \mathrm{Wh} \mathrm{kg}^{-1}$ ) is only comparable to lead acid and nickel-metal hydride batteries, which is less than half of the specific energy of high performance batteries like lithium-ion (180 $\mathrm{Wh} \mathrm{kg}^{-118}$ ).

When using graphite electrodes, there is a partial irreversible intercalation of anions, especially during the initial charge and discharge cycles. After the first cycles, the capacity remains stable without a 
Table I. Battery components (positive/negative electrodes and electrolyte) and characteristic battery values (measured cell voltage, specific capacity, energy and power) for rechargeable aluminum batteries with a charge-storage material as positive electrode.

\begin{tabular}{|c|c|c|c|c|c|c|}
\hline Positive electrode & $\begin{array}{l}\text { Negative } \\
\text { electrode }\end{array}$ & Electrolyte & $\begin{array}{l}\text { Average cell } \\
\text { voltage/V }\end{array}$ & $\begin{array}{l}\text { Specific discharge } \\
\text { capacity/ } \mathrm{Ah} \mathrm{kg}^{-1}\end{array}$ & $\begin{array}{l}\text { Specific } \\
\text { energy/Wh kg } \mathrm{kg}^{-1}\end{array}$ & Reference \\
\hline Graphite & Al foil & $\begin{array}{l}\text { Lewis acidic } \\
\text { EMImCl-AlCl }\end{array}$ & $1.7-2$ & $70-148$ & $40-64$ & $1-5$ \\
\hline $\begin{array}{l}\text { Zeolite-templated } \\
\text { carbon }\end{array}$ & Al foil & $\begin{array}{l}\text { Lewis acidic } \\
\text { EMImCl- } \mathrm{AlCl}_{3}\end{array}$ & Sloping $\sim 1.05$ & $\mathrm{n} / \mathrm{a}$ & 64 & 37 \\
\hline Oxides, sulfides & $\begin{array}{l}\text { Al foil and } \\
\text { plate }\end{array}$ & $\begin{array}{l}\text { Lewis acidic BMImCl- } \\
\text { and EMImCl-AlCl } 3\end{array}$ & Sloping $\sim 0.7-0.5$ & $46-273$ & $40-90$ & $7-12,38,39$ \\
\hline PPy on glassy carbon & $\mathrm{Al}$ foil & $\begin{array}{l}\text { Lewis acidic } \\
\text { EMImCl- } \mathrm{AlCl}_{3}\end{array}$ & Sloping above $\sim 1$ & $30-100$ & 46 & 14 \\
\hline $\begin{array}{l}\text { PEDOT on glassy } \\
\text { carbon }\end{array}$ & $\mathrm{Al}$ foil & $\begin{array}{l}\text { Lewis acidic } \\
\text { EMImCl-AlCl }\end{array}$ & $\begin{array}{l}\text { Slightly sloping } \\
\text { above } \sim 1\end{array}$ & $30-100$ & 44 & 14 \\
\hline $\begin{array}{l}\text { PEDOT on glassy } \\
\text { carbon }\end{array}$ & Al plate & $\begin{array}{l}\text { Lewis acidic } \\
\text { EMImCl-AlCl }\end{array}$ & $\begin{array}{l}\text { Slightly sloping } \\
\text { above } \sim 1\end{array}$ & $84-282$ & $84-282$ & 15 \\
\hline PAn on platinum & Al rod & $\begin{array}{l}\text { Lewis acidic } \mathrm{BPCl}-\mathrm{AlCl}_{3} \\
\text { and } \mathrm{EMImCl}-\mathrm{AlCl}_{3}\end{array}$ & $<1.6$ & $45-68$ & $\mathrm{n} / \mathrm{a}$ & 40 \\
\hline
\end{tabular}

significant drop in performance. It is assumed that an activation process and adaption of the graphite structure takes place within the first cycles causing partial irreversibility. ${ }^{4}$

Battery systems based on a conductive polymer and aluminum.Conductive polymers like poly(thiophene) (PEDOT), poly(pyrrole) (PPy) and poly(aniline) (PAn) have the ability to store high amounts of charge while acting as capacitor and battery simultaneously. ${ }^{15}$ These hybrid battery-capacitors combine the oxidation/reduction faradaic process of the conductive polymer and the non-faradaic behavior of doping/de-doping anions into the polymer. The non-faradaic charges stored depends on the thickness and porosity of the conductive polymer and is therefore and important parameter of the material. Hybrid battery-capacitors are potentially positive electrode materials for high performance batteries, which require high capacities and cell potentials.

The use of conductive polymers as anion intercalation material has already been demonstrated in lithium-ion batteries showing high coulombic efficiencies of up to $99 \%$ and energy densities $\left(280-420 \mathrm{Wh} \mathrm{kg}^{-1}\right){ }^{15}$ There are few studies of conductive polymers coupled with aluminum, as the positive and negative electrodes respectively, in the ionic liquids 1-ethyl-3-methylimidazolium chloride $\left(\mathrm{EMImCl}-\mathrm{AlCl}_{3}\right)^{14}$ and 1-butylpyridinium chloride (BPCl- $\left.\mathrm{AlCl}_{3}\right)$ showing energy densities between 44-282 $\mathrm{Wh} \mathrm{kg}^{-1}$ (Table I).

The charging reaction (Equation 3$)^{15}$ of the positive polymer electrode is characterized by the change from neutral to positively charged state of the conductive polymer (CP) electrode and the simultaneous insertion of anions $\left(\mathrm{X}^{-}\right)$(anion doping). The amount of doped anions is defined as degree of doping $\alpha$ from 0 to 1 and describes the number of monomer units in the polymer that accommodate one doping anion. The conductive polymer oxidizes during the charging cycle generating positively charged centers that are neutralized by the anions of the chloroaluminate ionic liquid $\left(\mathrm{Cl}^{-}, \mathrm{AlCl}_{4}^{-}, \mathrm{Al}_{2} \mathrm{Cl}_{7}^{-}\right)$. The nature of the anion doping species depends on the composition of the chloroaluminate ionic liquid (Table I). During the discharge reaction (Equation 3), ${ }^{15}$ the positive electrode releases the anions to the electrolyte converting the conductive polymer back to the uncharged/neutral state.

$\mathrm{CP}_{1 / \alpha}+\mathrm{X}_{\text {discharge }}^{\stackrel{\text { charge }}{\rightleftharpoons}}[\mathrm{CP}]_{1 / \alpha} \mathrm{X}+\mathrm{e}^{-} \quad \mathrm{X}^{-}=\mathrm{Cl}^{-}, \mathrm{AlCl}_{4}^{-}, \mathrm{Al}_{2} \mathrm{Cl}_{7}^{-}$

The reversibility of the charge and discharge reaction depends significantly on the positive electrode and could take place within a potential window of $2.6 \mathrm{~V}$ vs. $\mathrm{Al} / \mathrm{Al}$ (III) for polythiophene and polypyrrole. ${ }^{14}$ Over-oxidation of the polymer at high anodic potentials leads to a degradation of the conductive polymer due to nucleophilic attack of the ionic liquid, while high negative cathodic potentials enable the doping of cation (n-doping) of the conductive polymer. ${ }^{41}$ The doping/de-doping reaction occurs at different electrode potentials, which are important for the charge and discharge cell voltage of the battery. The doping/charge and de-doping/discharge electrode potentials are preferred to be as positive as possible in order to be far from the aluminum deposition/dissolution process but close to each other to increase the cell potential and the performance of the battery.

The synthesis path of the conductive polymer influences the cycle stability of the battery. Conductive polymers films prepared chemically with a binder, show lower cycle stability and reversibility than those synthesized at constant current or potential electrolysis on vitreous carbon. ${ }^{14}$ In addition, the polymerization media, aqueous or nonaqueous, has a significant influence on the reversibility and degradation. The films synthesized in aqueous electrolytes can suffer damages if small amount of water remains in the structure because the hygroscopic chloroaluminate ionic liquid can form hydrochloric acid during cycling, which could cause detachment of the film from the substrate. For example, a detached polythiophene was observed as blue cloudlike film. ${ }^{15}$ A better approach is the direct synthesis of the conductive polymers in chloroaluminate ionic liquids. ${ }^{14}$ The films show high reversibility and high mechanical stability than those prepared in aqueous solutions or conventional organic solvents like acetonitrile. ${ }^{41,42}$ The surface structure of an electro-polymerized polythiophene film on a planar vitreous carbon substrate appears as granular agglomerate structures both in aqueous and ionic liquid electrolytes.

Quartz crystal microbalance studies consistently show that a mixture of anionic species of the ionic liquid intercalates into the conductive polymer during electro-polymerization and cycling. Larger anion species like $\mathrm{AlCl}_{4}{ }^{-}$and $\mathrm{Al}_{2} \mathrm{Cl}_{7}{ }^{-}$could have a significant influence on the capacity and stability of the conductive polymer because they could remain trapped into the polymer structure if the pores are too small and impede the reversible shuttling of the doping anions. It is also reported that the conductive polymer is affected by swelling due to the size of the anions of the chloroaluminate ionic liquid. ${ }^{14,15,38,40}$ The swollen polymer films could offer higher porosity and ability to accommodate bulky anions. Moreover, three-dimensional conductive polymer electrodes with a high surface area are suggested to create more space as well as higher number of doping positions and accommodate more doping anions, which will increase the capacity and the specific power of the battery system. ${ }^{15}$

\section{Conclusions}

Aluminum based batteries using non-aqueous electrolytes like ionic liquids at room temperature are promising alternatives for high performance batteries. 
The main characteristics of these systems are:

(a) The deposition and dissolution of aluminum at the negative electrode in a Lewis acidic chloroaluminate ionic liquid has been studied in detail and shows high reversibility and microcrystalline depositions, which do not cause dendrite growth avoiding short circuit the battery.

(b) Several charge-storage materials like graphite, zeolites, oxides, sulfides and conductive polymers have been reported. However, positive electrodes based on graphite, oxides and sulfides are characterized by low specific capacity or low and sloping cell voltages, whereas conductive polymers show higher specific capacities and specific energies.

(c) The influence of the type of conductive polymer positive electrode on the battery performance needs further studies to address the effect of different substrate materials and preparation methods.

(d) A major challenge in this system is the intercalation of bulky anions in the conductive polymer, which decrease the cycle stability of the conductive polymer. Therefore, the preparation of conductive polymer-carbon composites on three-dimensional substrates seems promising due to their larger surface area that could potentially accommodate a higher number of intercalation anions, leading to a higher electrode capacity and battery performance.

\section{Acknowledgment}

The authors thank for the financial support of the Centre for Doctoral Training in Sustainable Infrastructure Systems from the University of Southampton [EP/L01582X/1] and the Lloyd's Register Foundation International Consortium of Nanotechnologies (LRF-ICON).

\section{ORCID}

\section{A. Bund (i) https://orcid.org/0000-0001-9837-2408}

\section{References}

1. G. A. Elia, I. Hasa, G. Greco, T. Diemant, K. Marquardt, K. Hoeppner, R. J. Behm, A. Hoell, S. Passerini, and R. Hahn, 'Insights into the reversibility of aluminum graphite batteries', Journal of Materials Chemistry A, 5, 9682 (2017).

2. P. R. Gifford and J. B. Palmisano, 'An aluminum/chlorine rechargeable cell employing a room temperature molten salt electrolyte', Journal of the Electrochemical Society, 135, 650 (1988)

3. J. V. Rani, V. Kanakaiah, T. Dadmal, M. Srinivasa Rao, and S. Bhavanarushi, 'Fluorinated natural graphite cathode for rechargeable ionic liquid based aluminum-ion battery', Journal of the Electrochemical Society, 160, A1781 (2013).

4. M. C. Lin, M. Gong, B. Lu, Y. Wu, D. Y. Wang, M. Guan, M. Angell, C. Chen, J. Yang, B. J. Hwang, and H. Dai, 'An ultrafast rechargeable aluminum-ion battery', Nature, Letter, 520, 325 (2015)

5. K. V. Kravchyk, S. Wang, L. Piveteau, and M. V. Kovalenko, 'Efficient aluminum chloride-natural graphite battery', Chemistry of Materials, 29, 4484 (2017).

6. S. Ahmad, M. Deepa, and S. Singh, 'Electrochemical synthesis and surface characterization of poly(3,4-ethylenedioxythiophene) films grown in an ionic liquid', Langmuir, 23, 11430 (2007).

7. N. Jayaprakash, S. K. Das, and L. A. Archer, 'The rechargeable aluminum-ion battery', The Royal Society of Chemistry, Chemical Communications, 47, 12610 (2011)

8. W. Wang, B. Jiang, W. Xiong, H. Sun, Z. Lin, L. Hu, J. Tu, J. Hou, H. Zhu, and S. Jiao, 'A new cathode material for super-valent battery based on aluminum ion intercalation and deintercalation', Nature, Scientific Reports, 3, 3 (2013).

9. L. D. Reed and E. Menke, 'The roles of V2O5 and stainless steel in rechargeable Al-ion batteries', Journal of the Electrochemical Society, 160, A915 (2013).

10. M. Chiku, H. Takeda, S. Matsumura, E. Higuchi, and H. Inoue, 'Amorphous vanadium oxide/carbon composite positive electrode for rechargeable aluminum battery', ACS Applied Materials and Interfaces, 7, 24385 (2015).

11. H. Wang, Y. Bai, S. Chen, X. Luo, C. Wu, F. Wu, J. Lu, and K. Amine, 'Binder-free V2O5 cathode for greener rechargeable aluminum battery', ACS Applied Materials and Interfaces, 7, 80 (2015).

12. T. Mori, Y. Orikasa, K. Nakanishi, C. Kezheng, M. Hattori, T. Ohta, and Y. Uchimoto, 'Discharge/charge reaction mechanisms of FeS2 cathode material for aluminum rechargeable batteries at $55^{\circ} \mathrm{C}^{\prime}, \mathbf{3 1 3}, 9$ (2016).
13. T. Gao, X. Li, X. Wang, J. Hu, F. Han, X. Fan, L. Suo, A. J. Pearse, S. Bok Lee, G. W. Rubloff, K. J. Gaskell, M. Noked, and C. Wang, 'A rechargeable Al/S battery with an ionic-liquid electrolyte', Angewandte Chemie, 128, 10052 (2016).

14. N. S. Hudak, 'Choroaluminate-doped conducting polymers as positive electrodes in rechargeable aluminum batteries', The Journal of Physical Chemistry, 118, 5203 (2014).

15. T. Schoetz, C. Ponce de Leon, A. Bund, and M. Ueda, 'Preparation and characterization of a rechargeable battery based on poly-(3,4-ethylenedioxythiophene) and aluminum in ionic liquids', Journal of Solid State Electrochemistry, 2017.

16. J. N. Rauch, 'Global mapping of $\mathrm{Al}, \mathrm{Cu}, \mathrm{Fe}$ and $\mathrm{Zn}$ in-use stocks and in-ground resources', U. S. Geological Survey; Reston VA, 2009.

17. R. Revel, T. Audichon, and S. Gonzalez, 'Non-aqueous aluminum-air battery based on ionic liquid electrolyte', Journal of Power Sources, 272, 415 (2014).

18. R. Korthauer, 'Handbook lithium-ion-batteries,', Springer-Verlag Berlin Heidelberg, 2013.

19. E. Budevski, I. Iliev, and A. Kaisheva, 'Investigations of a large-capacity mediumpower saline aluminum-air battery', Journal of Applied Electrochemistry, 19, 323 (1989).

20. D. Egan, C. Ponce de Leon, R. J. K. Wood, R. L. Jones, K. R. Stokes, and F. C. Walsh, 'Developments in electrode materials and electrolytes for aluminum-air batteries', Journal of Power Sources, 236, 293 (2013).

21. Q. Li and N. J. Bjerrum, 'Aluminum as anode for energy storage and conversion: a review', Journal of Power Sources, 110, 1 (2002)

22. B. Vestergaard, N. J. Bjerrum, J. Niels, I. Petrushina, H. A. Hjuler, R. W. Berg, and M. Begtrup, 'Molten triazolium chloride systems as new aluminum battery electrolytes', Journal of the Electrochemical Society, 140, 3108 (1993).

23. J. F. Equey, S. Mueller, A. Tsukada, and $\mathrm{O}$. Haas, 'Al/Cl2 battery with slightly acidic $\mathrm{NaCl}$ electrolyte. I. Porous graphite chlorine electrodes', Journal of Applied Electrochemistry, 19, 65 .

24. M. Galiński, A. Lewandowski, and I. Stępniak, 'Ionic liquids as electrolytes', Electrochimica Acta, 51, 5567 (2006).

25. D. R. MacFarlane, J. M. Pringle, P. C. Howlett, and M. Forsyth, 'Ionic liquids and reactions at the electrochemical interface', Physical Chemistry Chemical Physics, 12, 1659 (2010).

26. A. A. Fannin Jr., D. A. Floreani, L. A. King, J. S. Landers, B. J. Piersma, D. J. Stech, R. L. Vaughn, J. S. Wilkes, and J. L. Williams, 'Properties of 1,3-dialkylimidazolium chloride-aluminum chloride ionic liquids. 2. phase transitions, densities, electrical conductivities and viscosities', Journal of Physical Chemistry, 12, 2614 (1984).

27. H. Ohno, 'Electrochemical aspects of ionic liquids,', John Wiley \& Sons, Hoboken, New Jersey, 2005.

28. H. L. Ngo, K. LeCompte, L. Hargens, and A. B. McEwen, 'Thermal properties of imidazolium ionic liquids', Thermochimica Acta, 357-358, 97 (2000).

29. M. Ueda, S. Hariyama, and T. Ohtsuka, 'Al electroplating on the AZ121 Mg alloy in an EMIC-AlCl3 ionic liquid containing ethylene glycol', Journal of Solid State Electrochemistry, 16, 3423 (2012)

30. M. C. Buzzeo, R. G. Evans, and R. G. Compton, 'Non-haloaluminate roomtemperature ionic liquids in electrochemistry-a review', A European Journal of Chemical Physics and Physical Chemistry, 5, 1106 (2004).

31. L. Fu, N. Li, Y. Liu, W. Wang, Y. Zhu, and Y. Wu, 'Advances of aluminum based energy storage systems', Chinese Journal of Chemistry, 35, 13 (2017).

32. T. Jiang, M. J. Chollier Brym, G. Dubé, A. Lasia, and G. M. Brisard, 'Electrodeposition of aluminum from ionic liquids: Part I-electrodeposition and surface morphology of aluminum from aluminum chloride $\left(\mathrm{AlCl}_{3}\right)$-1-ethyl-3-methylimidazolium chloride (EMIm] Cl) ionic liquids', Surface and Coatings Technology, 201, 1 (2006).

33. F. Endres, 'Ionic Liquids: solvents for the electrodeposition of metals and semiconductors', Journal of Chemical Physics and Physical Chemistry, 3, 144 (2002).

34. J. D. Holbrey and K. R. Seddon, 'Ionic liquids', Clean Products and Processes, 1, 223 (1999).

35. W. Lu, A. G. Fadeev, B. Qi, E. Smela, B. R. Mattes, J. Ding, G. M. Spinks, J. Mazurkiewicz, D. Zhou, G. G. Wallace, D. R. MacFarlane, S. A. Forsyth, and M. Forsyth, 'Use of ionic liquids for pi-conjugated polymer electrochemical devices', Science, 297, 983 (2002)

36. F. Endres and S. Z. El Abedin, 'Air and water stable ionic liquids in physical chemistry', Physical Chemistry Chemical Physics, 8, 2101 (2006).

37. N. P. Stadie, S. Wang, K. V. Kravchyk, and M. V. Kovalenko, 'Zeolite-templated carbon as an ordered microporous electrode for aluminum batteries', ACS Nano, 11, 1911 (2017).

38. S. Choi, H. Go, G. Lee, and Y. Tak, 'Electrochemical properties of an aluminum anode in an ionic liquid electrolyte for rechargeable aluminum-ion batteries', Physical Chemistry Chemical Physics, 19, 8653 (2017).

39. L. Geng, G. Lv, X. Xing, and J. Guo, 'Reversible electrochemical intercalation of aluminum in Mo6S8', Chemistry of Materials, 27, 4926 (2015).

40. N. Koura, H. Ejiri, and K. Takeishi, 'Polyaniline secondary cells with ambient temperature molten salt electrolyte', Journal of the Electrochemical Society, 140, 602 (1993).

41. J. Ding, D. Zhou, and G. Wallace, 'Use of ionic liquids as electrolytes in electromechanical actuator systems based on inherently conducting polymers', Chemistry of Materials, 15, 2392 (2003).

42. K. Wagner, J. M. Pringle, S. B. Hall, M. Forsyth, D. R. MacFarlane, and D. L. Officer, 'Investigation of the electropolymerisation of EDOT in ionic liquids', Synthetic Materials, 153, 257 (2005). 